\title{
Building the assets to thrive: Addressing the HIV-related vulnerabilities of adolescent girls in Ethiopia-Policy Brief
}

Population Council

Follow this and additional works at: https://knowledgecommons.popcouncil.org/departments_sbsr-pgy

Part of the Demography, Population, and Ecology Commons, Family, Life Course, and Society Commons, and the International Public Health Commons How does access to this work benefit you? Let us know!

\section{Recommended Citation}

"Building the assets to thrive: Addressing the HIV-related vulnerabilities of adolescent girls in Ethiopia-Policy Brief." New York: Population Council, 2014. 
When HIV prevention programs are shaped by evidence and designed for replication and scale-up, they can reach large numbers of the girls and young women at greatest risk and increase their ability to avoid infection.

In Eastern and Southern Africa, HIV is the leading cause of death among girls aged 15-19. Despite decades of investment and substantial progress against HIV, adolescent girls remain at disproportionate risk of infection.

Few programs have sought to take a "whole girl" approach to addressing the multiple vulnerabilities to HIV infection-social isolation, economic insecurity, lack of access to services, and sexual and gender-based violence-experienced by the most marginalized adolescent girls in the poorest communities in Africa.

Building the Assets to Thrive: Addressing the HIV-related Vulnerabilities of Adolescent Girls in Ethiopia is a comprehensive review of three programs implemented and evaluated by the Population Council and the Ethiopian government beginning in 2007: Biruh Tesfa, Meseret Hiwott, and Addis Birhan. These programs seek to reduce Ethiopian girls' HIV risk by using similar methods to engage girls-and, in the case of one program, the males who play a role in their health and well-being.

This policy brief summarizes Building the Assets to Thrive to provide policymakers and program planners with a road map for creating and supporting evidence-based, locally responsive, simple, effective, scalable, and sustainable programs that produce positive outcomes for girls and their communities.

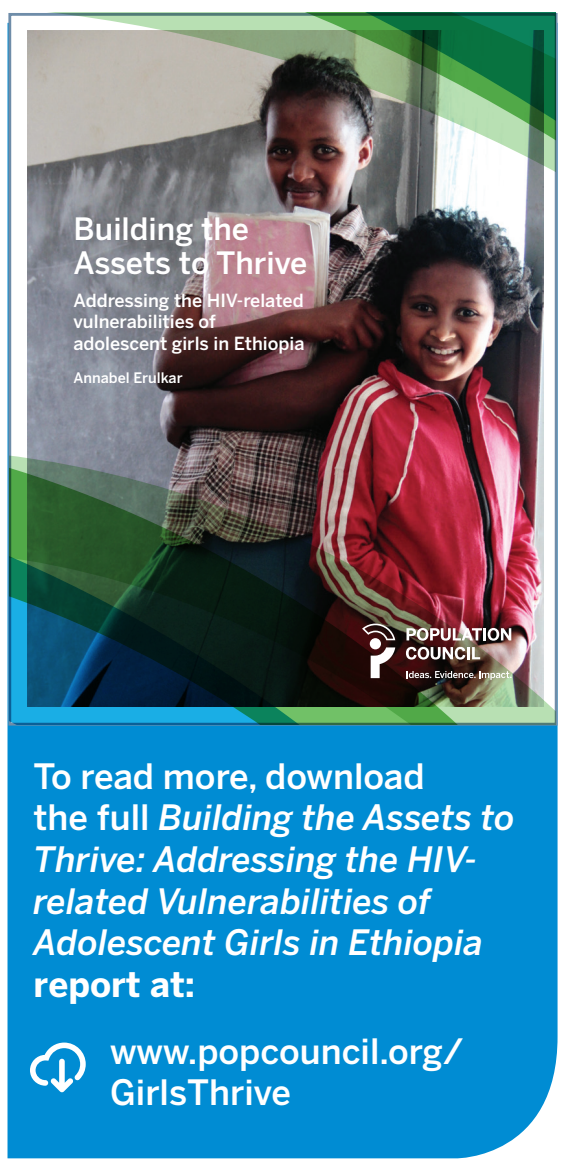

To read more, download the full Building the Assets to Thrive: Addressing the HIV related Vulnerabilities of Adolescent Girls in Ethiopia report at:

www.popcouncil.org/ GirlsThrive 


\section{Evidence-based programs}

The foundation of the Population Council's work in Ethiopia began in the early 2000s with extensive formative research: quantitative, population-based surveys among adolescents in the urban slums of Addis Ababa and remote, rural Amhara Region to understand the circumstances of the most vulnerable populations.

The Council and the Ethiopian Ministry of Youth and Sports (now the Ethiopian Ministry of Women, Children, and Youth Affairs) found that adolescent girls who were married or were rural-to-urban migrants/domestic workers were the most vulnerable. In response, we developed programs for these populations: Biruh Tesfa, Meseret Hiwott, and Addis Birhan. These programs reach different participants in different geographic areas, but they share many similarities that can be adapted to the design, implementation, and evaluation of programs to benefit adolescent girls elsewhere.

\section{Biruh Tesfa (Bright Future)}

Biruh Tesfa seeks to improve girls' ability to protect themselves by reducing their social isolation and providing them with assets, such as a safe space to gather, caring and trustworthy adult mentors, friends, health information, services to reduce sexual exploitation and abuse, and functional literacy skills.

Girls gather in mentor-led groups according to age and educational level. In the meetings, mentors can offer education on HIV and AIDS and related issues, as well as nonformal education and links to health services.

The program serves out-of-school adolescent girls and young women aged 7-24 in urban slums.

\section{PROGRAM IMPACT}

- Reached more than 63,000 extremely vulnerable girls in 18 cities by 2013

- Girls in the program sites were twice as likely as girls in the control site to:

- report having social support

- score highly on HIV knowledge questions

- know where to obtain voluntary HIV counseling and testing

- want to be tested

\section{What is an asset?}

An asset is a store of value-a valuable thing-that girls can use to reduce vulnerabilities and expand opportunities. For example, self-esteem is an asset. A girl can draw on her self-esteem to negotiate for safer sex or to excel at a job interview. Another asset is savings. A girl can use her savings in the case of illness to pay the hospital bill instead of acquiring the money in a risky way. Savings can also be used to pay for vocational training. We can think about assets in different categories:
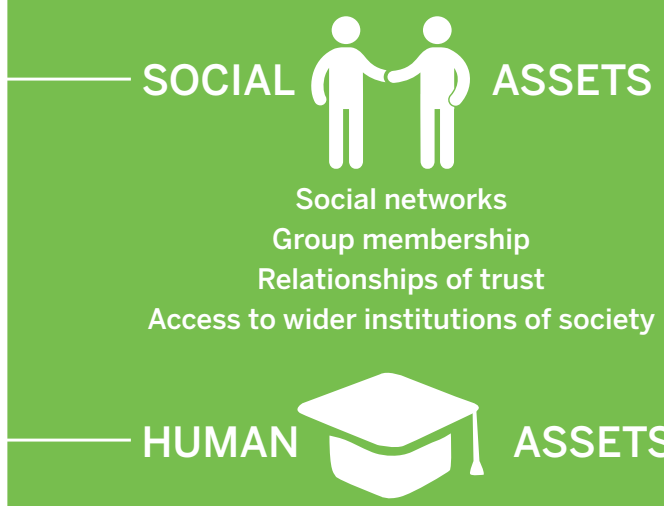

ASSETS

Skills and knowledge

Good health

Ability to work Self-esteem

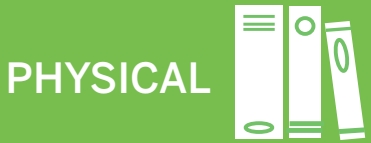

Personal assets

(clothing, jewelry, mobile phone, household items) Land

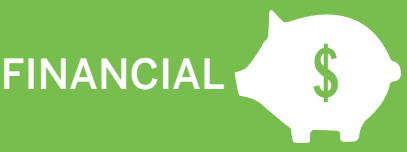

ASSETS

\section{ASSETS}

Transport

Tools, equipment, and other productive assets 
Meseret Hiwott mobilizes married adolescent girls and young women aged 10-24 in rural areas. The program provides them with a safe space to gather; adult female mentors; information on HIV and AIDS and related issues, gender and power dynamics, and spousal communication; training in financial literacy; and links to health services, including family planning.

Addis Birhan, an offshoot of Meseret Hiwott, is designed to support the goals of that program. Addis Birhan was launched in response to community demand. It gathers men and boys aged 10-85 who are married to adolescent girls into discussion groups that focus on promoting caregiving to wives and children and addressing extramarital partnerships, alcohol abuse, and violence.

\section{PROGRAM IMPACT}

- Addis Birhan: Reached more than 135,000 boys and men by 2013

- Meseret Hiwott: Reached more than 230,000 girls and young women by 2013. Girls in the program sites were significantly more likely than other girls to:

- obtain voluntary HIV counseling and testing

- use family planning

- negotiate spousal accompaniment to clinic visits

- receive assistance with domestic work from their husbands

- Girls and young women from couples in which both the husband and wife participated in the groups benefitted more than girls and young women in couples in which the husband did not participate

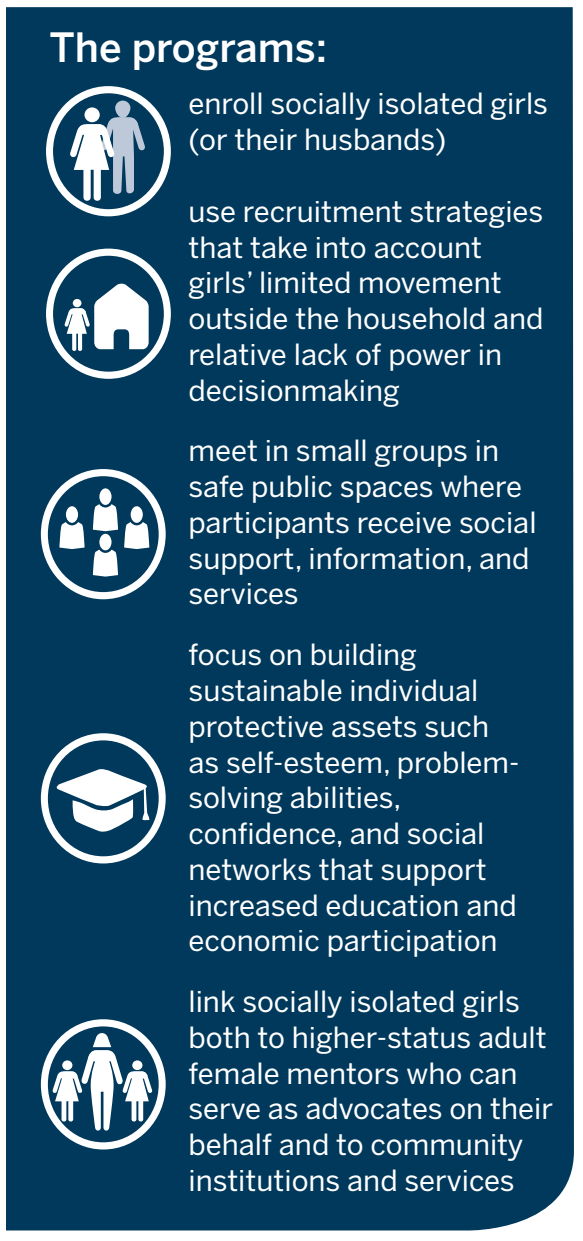

\section{In sum}

Population Council evaluations indicate that girls in these programs are building their social capital and protective assets in ways that reduce their HIV risk and increase their prospects for a safe and more productive life. Our results also demonstrate that when evidence-based insights about girls' circumstances are used to inform program design, participants, gatekeepers, and the community respond positively and the programs can be scaled up successfully.

Key to the success of these programs are persistence and political will in the face of skepticism, both of which are engendered by close collaboration with the local ministries and community groups that will one day be responsible for expanding the programs regionally and nationwide.

Well-designed programs-based on thorough formative research, planned to be replicable and scalable, carefully monitored and adjusted, and taking a "whole girl" approach-are effective in reducing risk factors for and increasing assets that are protective against HIV. These programs were successful with the most marginalized and hardest to reach girls in the poorest areas, such as married girls in rural areas and child domestic workers and migrants in urban areas.

Despite early skepticism from development professionals about whether these girls and young women could be reached, the Population Council's experience shows that there is an appetite for these programs not only among vulnerable adolescent girls but also among the husbands and, eventually, employers of these girls.

\section{PARTNER ORGANIZATIONS}

Government agencies

Federal Ministry of Women, Children, and Youth Affairs (formerly Youth and Sports); Regional Bureaus of Women, Children, and Youth Affairs in Addis Ababa, Amhara, and Tigray
Local faith-based and nongovernmental organizations Ethiopian Orthodox Church; Ethiopian Muslim Developmental Agency; Ethiopian Women with Disabilities National Association; Nia Foundation; Organization for Protection and Rehabilitation of Female Street Children
International NGOs

YWCA; Handicap International

Donors

USAID/PEPFAR; UN Foundation; UNFPA; Nike Foundation; World Bank; Italian Trust Fund for Children and Youth in Africa; George and Patricia Ann Fisher Family Foundation 


\section{Six Steps to Effective Programs for Girls}

The Population Council's experience in Ethiopia and elsewhere suggests the following six strategies are essential to the success of programs aimed at reducing gender inequalities and vulnerabilities:

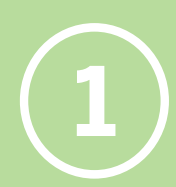

\section{Conduct and carefully link} formative research findings to program design.

Formative research, particularly population-based surveys, can be used to understand the circumstances and needs of local populations, identify those at highest risk of the worst outcomes, and shape program design to reach target groups. By developing programs that address the priorities and needs of target populations, program managers can increase the likelihood of program participation and effectiveness.

\section{Employ mentors.}

The mentorship model builds trust and inspiration among program participants, who often lack caring, protective adults in their lives. Mentors can serve as trusted adults to participants and also as higherstatus advocates for girls.

\section{Tailor recruitment and}

\section{involve community gatekeepers.}

Because girls in many settings have far more limited mobility than boys, program mentors can reach and enroll them by going house to house-a method traditionally used by health extension workers. This method of recruitment not only results in reaching a higher proportion of a population in need of program services, but also allows mentors to negotiate with gatekeepers and observe and understand the home circumstances of the girls in their groups.

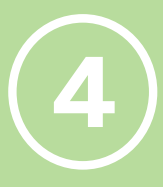

\section{Measure girls' protective assets as indicators of program success.}

Research has identified several types of protective assets, for example, friendship networks, ID cards, and a shelter in which to spend the night in an emergency. These assets can and should be measured and documented.

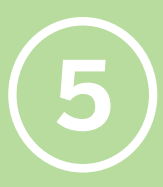

\section{Monitor and evaluate programs.}

Monitoring and evaluation must be integral and dynamic elements of any successful program, to generate the evidence required to identify best practices, refine critical program elements, and eliminate ineffective approaches. Qualitative monitoring after programs are underway can provide important information for improving programs-for example, to explore new areas for expansion or program modification.

\section{Design for scale-up by encouraging local ownership.}

Foster program sustainability by collaborating closely with local partners, including government agencies. The sharing of knowledge and ownership is critical, since local partners will ultimately be responsible for conducting programs. Recruit leaders from within the community to serve as mentors for program participants. Engaging large numbers of local residents creates lasting, normative changes within a community. 